\title{
Effect of Gamma Irradiation on Microbial Quality of Minimally Processed Product in Tunisia: A Case of Ready to Eat Salad
}

\author{
Rahmani F',2, Yahya M', Jebri S*, Amri I', Mejri \\ $A^{3}$, Hamdi $M^{4}$ and Hmaied $F^{1}$ \\ 'Tunis El Manar University, National Center of Nuclear \\ Sciences and Technologies (CNSTN), Tunisia \\ ${ }^{2}$ Tunis El Manar University, Tunisia \\ ${ }^{3}$ Ionizing Radiation Dosimetry Laboratory, National \\ Center for Nuclear Sciences and Technologies (CNSTN), \\ Tunisia \\ ${ }^{4}$ University of Carthage, National Institute of Applied \\ Sciences of Tunis (INSAT), Tunisia \\ *Corresponding author: Sihem J ebri Cnstn, Tunis El \\ Manar University, National Center of Nuclear Sciences \\ and Technologies (CNSTN), BP 2020, Sidi Thabet, \\ Tunisia
}

Received: J anuary 24, 2021; Accepted: March 15, 2021; Published: March 22, 2021

\begin{abstract}
The use of gamma irradiation in food safety management as a tool to improve the microbiological quality of food products. Minimally processed product may contain a large number of spoilage microorganisms that constitute a potential health risk. In this study, raw carrot samples and fresh-cut products after each processing steps: water chlorination, peeling process and citric acid treatment were analyzed for the total aerobic plate count, Staphylococcus spp., yeasts and molds. Ready to eat products were also analyzed for these selective pathogens. The freshly packaged carrot salads were irradiated at various doses $(0.5,1.0,2.0 \mathrm{kGy})$ and analyzed during 15 days storage period. The obtained results showed that raw carrots were highly contaminated by total aerobic plate count (7.23 $\left.\log _{10} / 25 \mathrm{~g}\right)$, Staphylococcus spp. (3.77 $\log _{10} / 25 \mathrm{~g}$ ), yeasts (5.62 $\log _{10} / 25 \mathrm{~g}$ ) and molds $\left(5.54 \log _{10} / 25 \mathrm{~g}\right)$. Washing treatment and peeling process, were able to reduce the concentration of total aerobic plate count by $2.23 \log _{10}$ and to remove Staphylococcus spp. and molds. The mean concentrations of total aerobic plate count, Staphylococcus spp. yeasts and molds were 4.87, $2.08,7.47$ and $2 \log _{10} / 25 \mathrm{~g}$ respectively for packaged salads. These results suggest that the contamination of carrot salads might occur through chain transformation. Regarding gamma irradiation effect, an optimal dose of 2 kGy offered a pathogen-free, hygienic product in comparison with controls. Furthermore it increased shelf-life by 4 to 9 days at refrigeration temperature. The validity of the processing treatment at $2 \mathrm{kGy}$ was challenged by artificially inoculating Staphylococcus aureus in the product.
\end{abstract}

Keywords: Ready to eat salad; Gamma irradiation; Total aerobic plate count; Yeasts and molds, Staphylococcus spp.; Processing steps

\section{Introduction}

In Tunisia, minimally processed product consumption is increasing, mainly fresh vegetables and fresh cut vegetables became one of the most important parts of the Tunisian food diet [1]. Vegetable salads usually used as a common supplement to urban fast food served in restaurants and canteens. The current pace of Tunisian community life pushes to the use of ready to eat vegetable products: they are offered in portions and can be consumed fast and easily [1]. Among Ready-to-Eat (RTE) vegetables, fresh salads do not undergo bactericidal heat treatment before consumption and may constitute potentially high-risk products. Consequently, spoilage microorganisms can proliferate in fresh vegetable salads and cause common foodborne diseases [2-4]. The first source of fruits and vegetables contamination is wastewater reuse in agriculture for irrigation and organic amendment of agricultural land [4-7]. In Tunisia, $43 \%$ of treated wastewater, are reused for an agricultural purpose such as irrigation of vegetable crops $[8,9]$. The microbiological contamination of fresh fruits and vegetables can occur throughout the food chain [10]. Hence, in the agri-food industry, the infected operator, who does not sufficiently respect the basic hygiene measures, can contaminate handled food products (processing, packaging, storage...) [11,12]. After the treatment of fruits and vegetables with citric acid and chlorination, the possibility of recontamination of these products is also possible [10,11]. It might occur through the formation of biofilms at the surface of the processing and packaging machinery or from the operators who have not followed the hygiene measures [13-15]. Total viable count, Staphylococcus spp. yeasts, and molds are known to dominate the microflora on fruits and vegetables [16]. Yeast and molds are spoilage microorganisms in carrot and could reach high concentrations in this product [17]. Staphylococcus spp. are considered as a biological hazard worldwide. They are potential pathogens causing several infections in human and animal. Staphylococcus spp. are also among common foodborne pathogens through the contamination of several foods such as fresh vegetables and dairy products $[1,18]$. Staphylococcus aureus is considered the third most important cause of disease in the world amongst the reported foodborne illnesses [19]. Staphylococcus aureus was responsible for $25 \%$ of all foodborne illnesses in the USA [20] and $5.1 \%$ of food poisoning outbreaks reported in Europe [21]. Several treatment methods are used to minimize health risks associated with collective food poisoning. Food irradiation is processing method used to improve the microbiological quality of several food types [3,22-24]. It is recommended to reduce the risk of food poisoning and extend food shelf life without detriment to health and with minimal effects on nutritional and sensory quality [25]. In this study, we aimed at 
evaluating the microbiological quality of carrot salads, evaluating the efficiency of treatment process throughout chain transformation and the effect of gamma irradiation on pathogenic microorganisms load.

\section{Material and Methods}

\section{Sample collection}

A total of 42 of minimally processed carrots were investigated in this study. In fact, 26 freshly carrot salad packaged in expanded polystyrene container $(22.5 \times 13,5 \mathrm{~cm})$ wrapped with the stretch film, were collected from an agri-food industry located in the north of Tunisia. The shelf life indicated on this product was 4 days. The treatment process used through chain transformation includes chlorination treatment, peeling process and citric acid treatment. 16 carrot samples were collected through processing treatment. Raw carrot samples $(n=4)$ as well as after each treatment: chlorination treatment $(n=4)$; peeling process $(n=4)$ and citric acid treatment $(\mathrm{n}=4)$. Samples were carried to the laboratory and processed within $24 \mathrm{~h}$.

\section{Irradiation of packaged carrot salad}

The freshly packaged carrot salad was irradiated at various doses $(0.5,1.0,2.0 \mathrm{kGy})$ using Cobalt 60 source at a dose rate of 5.305 $\mathrm{Gy} / \mathrm{min}$ and homogenization index of 1.05 . Nonirradiated samples served as controls. The effect of gamma irradiation was evaluated using artificially contamination of sterilized packaged carrot salad (exposed to 2kGy dose) by $106 \mathrm{CFU} / \mathrm{ml}$ of Staphylococcus aureus (ATCC 25823). The packaged carrot salad were dipped into the selective strain of Staphylococcus aureus for $10 \mathrm{~min}$ and repacked in a polystyrene container. The irradiated samples as well as controls, were stored during 15 days at refrigeration temperature $4^{\circ} \mathrm{C}$.

\section{Microbiological analysis}

Firstly, $25 \mathrm{~g}$ of each sample was diluted with $225 \mathrm{ml}$ of Peptone Water (Biokar diagnostics, France) and homogenized by stomacher (AES, 400ml) for $2 \mathrm{~min}$. Then, serial dilution was performed and $100 \mu \mathrm{l}$ from each dilution was dispensed onto Petri dishes with appropriate media in triplicate.

\section{Enumeration of total aerobic plate count}

The detection of total aerobic plate count was performed using Plate Count Agar (Biokar diagnostics, France) and incubated at $37^{\circ} \mathrm{C}$ for $24 \mathrm{~h}$.

\section{Isolation of Staphylococcus spp}

Staphylococcus spp. were isolated using Baird Parker medium supplemented with egg-yolk tellurite emulsion (Biokar diagnostics, France) and incubated at $37^{\circ} \mathrm{C}$ for $24 \mathrm{~h}$ to $48 \mathrm{~h}$.

\section{Yeast and molds isolation}

Yeast and molds counts were determined by surface spreading

of $0.1 \mathrm{~mL}$ sample on sabouraud chloramphenicol agar (Biokar, diagnostics, France). Incubation of the plates was performed at $25^{\circ} \mathrm{C}$ for 3-5 days.

\section{Data analysis}

Statistical analysis was performed using STATGRAPHICS Centurion XVI software version 16.2.04. Statistical data comparisons of pathogens concentrations after irradiation processing were conducted using Analysis of Variance (ANOVA) tests.

\section{Results}

After water chlorination process of raw carrots, the mean concentration of total aerobic plate count, Staphylococcus spp. yeasts and molds was decreased by $0.29 ; 1.25 ; 0.85$ and 1.04 $\log _{10} / 25 \mathrm{~g}$ respectively. The peeling process was able to decrease the concentration of total aerobic plate count and yeasts from previous process by 1.55 and $0.17 \log _{10}$. Also peeling process, was able to remove Staphylococcus spp. from carrot samples. After citric acid washing treatment Staphylococcus spp. and molds were not detected. Furthermore, this treatment reduced the mean concentration of total aerobic plate count and yeasts from peeling process by 0.39 and 0.21 $\log _{10} / 25 \mathrm{~g}$ respectively. After all processing steps, the microbiological profile of carrots showed, a decrease of total aerobic plate count and yeasts by 2.23 and $1.23 \log _{10} / 25 \mathrm{~g}$ respectively, a removal of Staphylococcus spp. and molds (Table 1 ). $\mathrm{D}_{10}$ values were determined, as dose of irradiation needed to elicita1-log 10 reduction of bacteria for irradiated samples. They are shown in Table 2 for each pathogens.

\section{Effect of gamma irradiation on total aerobic plate counts}

After gamma irradiation at various doses, the concentrations of total aerobic plate counts were determined during 15 days storage period (Figure 1). The mean concentration of total aerobic plate counts on packaged carrot salads used as control (unirradiated) was $4.87 \log _{10} / 25 \mathrm{~g}$. The dose of $0.5 \mathrm{kGy}$ showed a high reduction of total aerobic plate counts concentration which reached $2 \log _{10}$. After $1 \mathrm{kGy}$ and $2 \mathrm{kGy}$ doses exposition, total aerobic plate counts were removed from packaged carrot salad samples. During 5 days of storage period at $4^{\circ} \mathrm{C}$ (After 1 day from shelf life), total aerobic plate counts still present on fresh carrot salad control. Regarding irradiated samples at $0.5 \mathrm{kGy}$ and $1 \mathrm{kGy}$ doses, total aerobic plate count was detected

Table 2: $D_{10}$ values of pathogens in carrot

\begin{tabular}{|l|c|}
\hline \multicolumn{1}{|c|}{ Pathogens } & $\mathbf{D}_{\mathbf{1 0}}(\mathbf{k G y})$ \\
\hline Staphylococcus spp. & 0.21 \\
\hline Staphylococcus aureus ATCC 25823 & 0.64 \\
\hline Yeast & 0.75 \\
\hline Molds & 0.2 \\
\hline
\end{tabular}

Table 1: Microbiological profile of minimally processed carrots.

\begin{tabular}{|c|c|c|c|c|}
\hline \multirow[t]{2}{*}{ Pathogens } & \multirow{2}{*}{$\begin{array}{c}\text { Raw carrots } \\
\text { samples Mean }\left(\log _{10} \mathrm{CFU} / 25 \mathrm{~g}\right) \mathrm{n}=4\end{array}$} & \multicolumn{3}{|c|}{$\begin{array}{l}\text { Treatment processes } \\
\text { Mean }\left(\log _{10} \text { CFU/25g) }\right.\end{array}$} \\
\hline & & Water chlorination $n=40.5 \%$ & Peeling process $n=4$ & Citric acid treatment $(1 \mathrm{~g} / \mathrm{L}) \mathrm{n}=4$ \\
\hline Total aerobic plate count & 7.23 & 6.94 & 5.39 & 5 \\
\hline Staphylococcus spp. & 3.77 & 2.52 & - & - \\
\hline Yeasts & 5.62 & 4.77 & 4.6 & 4.39 \\
\hline Molds & 5.54 & 4.5 & 4.09 & - \\
\hline
\end{tabular}

- : not detected 


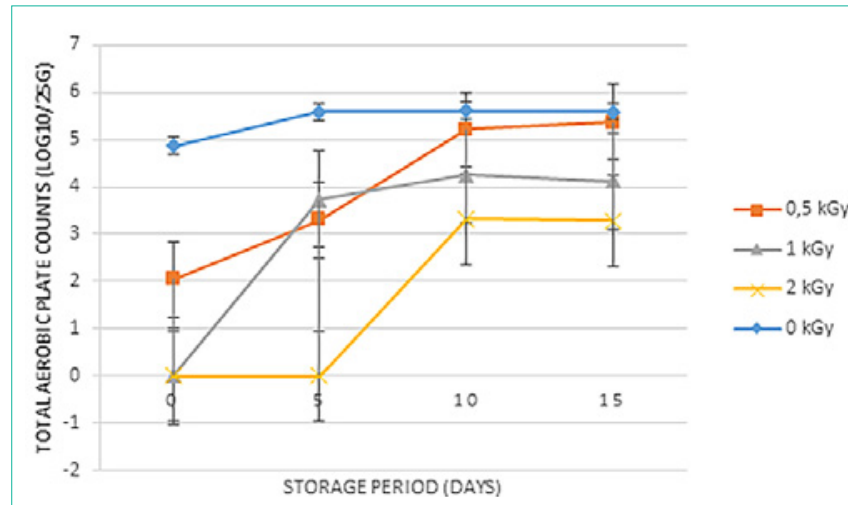

Figure 1: Concentration of Total aerobic plate counts in carrot salad treated with $0.5,1,2 \mathrm{kGy}$ and stored at $4^{\circ} \mathrm{C}$ for 15 days.

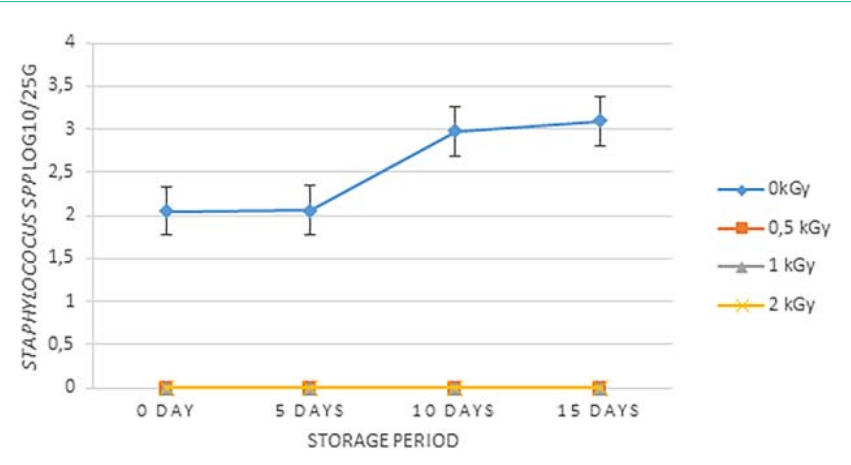

Figure 2: Concentration of Staphylococcus spp. in carrot salad treated with $0.5,1,2 \mathrm{kGy}$ and stored at $4^{\circ} \mathrm{C}$ for 15 days.

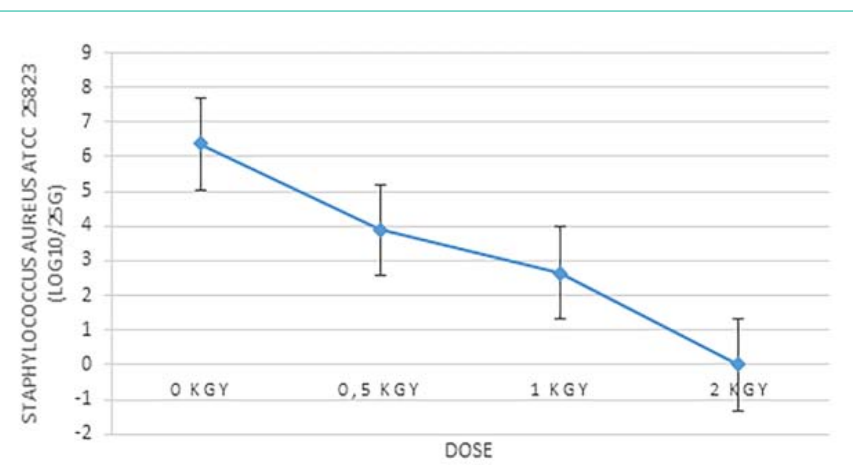

Figure 3: Concentration of Staphylococcus aureus in inoculated packed carrot treated with $0.5,1,2 \mathrm{kGy}$.

with mean concentration of 3.30 and $3.74 \log _{10}$ respectively. During 5 days storage period total aerobic plate counts were not detected on packaged carrot salad irradiated at $2 \mathrm{kGy}$ dose. After 10 days of storage period, total aerobic plate counts still growing on unirradiated samples. Regarding irradiated samples at $0.5 ; 1$ and $2 \mathrm{kGy}$ doses the concentration of total aerobic plate counts increased to reach 5.21; 4.26 and $3.32 \log _{10} / 25$ respectively. After 15 days storage period, total aerobic plate counts still detected on packaged carrot salad either for controls or irradiated samples. Statistical analysis showed that there was no significant difference between unirradiated and irradiated samples at $0.5 \mathrm{kGy}(\mathrm{P}=0.129)$ and $1 \mathrm{kGy}(\mathrm{P}=0.06)$ during 15 days. At $2 \mathrm{kGy}$, there was a statistical difference $(\mathrm{P}=0.008)$.

\section{Effect of gamma irradiation on Staphylococcus spp}

After gamma irradiation at various doses, the concentrations of Staphylococcus spp. were determined during 15 days storage period (Figure 2). The mean concentration of Staphylococcus spp. on packaged carrot salad used as control was $2.08 \log _{10} / 25 \mathrm{~g}$. The total removal of Staphylococcus spp. was carried out by exposition to 0.5 kGy dose. During 15 days of storage period, Staphylococcus spp. were not detected for irradiated samples at $0.5 ; 1$ and $2 \mathrm{kGy}$ doses. Regarding unirradiated packaged carrot salad, the concentration of Staphylococcus spp. increased by $1 \log _{10}$ during all storage period. There was a statistical difference between unirradiated and irradiated samples at various doses during 15 days storage period $(\mathrm{P}=0.0001)$.

Artificially contaminated sample was used as a positive control to confirm the dose which can remove high concentration of Staphylococcus from carrot salad. The initial concentration of contaminated control was $6.37 \log _{10} / 25 \mathrm{~g}$. The doses of 0.5 and $1 \mathrm{kGy}$ reduced initial concentration by 2.48 and $3.73 \log _{10}$ respectively. The total removal of contaminated control was obtained after exposition at $2 \mathrm{kGy}$ (Figure 3).

\section{Effect of gamma irradiation on yeasts}

After gamma irradiation at various doses, the concentrations of yeast were determined during 15 days storage period (Figure 4). They are the most dominant microorganism in the freshly packaged carrot salads. In fact, yeasts concentration on unirradiated samples reached spoilage level $\left(7.47 \log _{10} / 25 \mathrm{~g}\right)$. The reduction level obtained at $0.5 ; 1$ and $2 \mathrm{kGy}$ doses was about $3.5 ; 5.77$ and $4.91 \log _{10} / 25 \mathrm{~g}$ respectively. After 5 days storage period, yeasts count increased on unirradiated samples $\left(8.18 \log _{10} / 25 \mathrm{~g}\right)$. During this period, the concentration of yeasts increased on irradiated packaged carrot salad samples at 0.5 , 1 and $2 \mathrm{kGy}$ doses $\left(5.01 ; 4.21\right.$ and $2.61 \log _{10} / 25 \mathrm{~g}$ ) respectively. After 10 days storage period, the concentration of unirradiated samples still increasing to reach $8.56 \log _{10} / 25 \mathrm{~g}$ and during this period, yeasts still growing on irradiated samples at $0.5,1$ and $2 \mathrm{kGy}$ doses (Figure 4). Yeasts were able to grow during 15 days storage period, the concentration increased to reach $8,76 \log _{10} / 25 \mathrm{~g}$ for controls and they were detected on irradiated samples at $0.5 ; 1$ and $2 \mathrm{kGy}$ doses. Statistical results showed that there was a significant difference between irradiated and unirradiated control at $0.5 \mathrm{kGy}(\mathrm{P}=0.0015), 1$ $\mathrm{kGy}(\mathrm{P}=0.0052)$ and $2 \mathrm{kGy}(\mathrm{P}=0.0019)$ during 15 days storage period.

\section{Effect of gamma irradiation on molds count}

Molds were detected with low concentration $\left(2 \log _{10} / 25 \mathrm{~g}\right)$ on

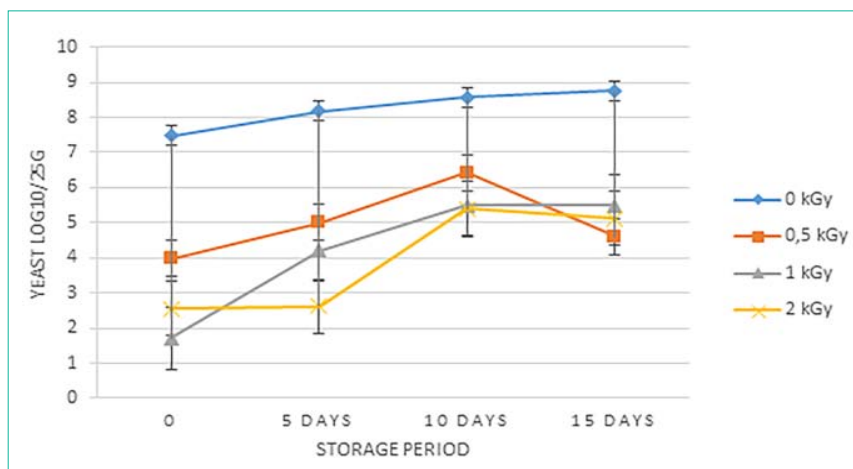

Figure 4: Concentration of yeasts in carrot salad treated with $0.5,1,2 \mathrm{kGy}$ and stored at $4^{\circ} \mathrm{C}$ for 15 days. 


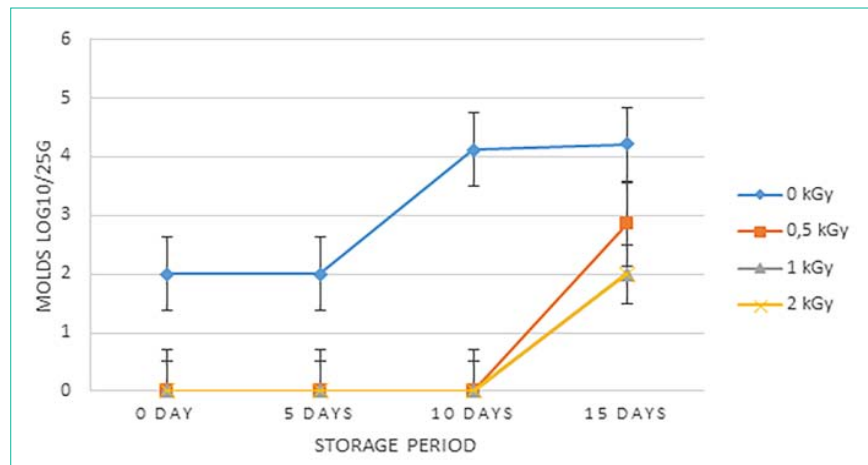

Figure 5: Concentration of molds in carrot salad treated with 0.5, 1, 2kGy and stored at $4^{\circ} \mathrm{C}$ for 15 days.

unirradiated fresh salad carrot samples as shown in Figure 5. The irradiation at $0.5 ; 1$ and $2 \mathrm{kGy}$ doses contributed to the total removal of molds. After 5 days storage period, the concentrations of molds maintained the same values. After 10 days of storage period, the concentration of molds on control samples increased to reach 4.12 $\log _{10} / 25 \mathrm{~g}$ (Figure 5). During this period, molds were not detected on irradiated samples at various doses. After 15 days storage period, the concentration of molds on unirradiated sample still around 4 $\log _{10} / 25 \mathrm{~g}$ and are about $2 \log _{10} / 25 \mathrm{~g}$ for irradiated samples at various doses. Statistical results showed a significant difference between unirradiated and irradiated samples at $0.5 \mathrm{kGy}(\mathrm{P}=0.046), 1 \mathrm{kGy}$ $(\mathrm{P}=0.018)$ and $2 \mathrm{kGy}(\mathrm{P}=0.018)$ during 15 days storage period.

\section{Discussion}

The main objective of this study was to improve the microbiological quality of freshly packaged salad and to provide a safe ready-to-eat food product for consumers. It has been demonstrated that the calorific value of fresh fruits and vegetables is not reduced by treatment with tolerated doses of ionizing radiation [26] (WHO, 1998). Irradiation of carrot salad inhibited the growth of aerobic microflora without loss of carotenes during storage $\left(10^{\circ} \mathrm{C}\right)$. Sensory analyses also pointed out the preference of the irradiated samples [24] (Barkai golan, 2017). In this study, raw carrot samples showed high contamination with total aerobic plate count, Staphylococcus spp. molds and yeast. This could be related to the use of contaminated water for irrigation or during harvesting. In our study, the concentration of spoilage bacteria for processed carrot such as total aerobic plate count is approximatelly similar as described previously by Maatta et al. [17]. Washing treatment and peeling process, were able to reduce the concentration of total aerobic plate count by $2.23 \log _{10}$ and to remove Staphylococcus spp. and molds. Peeling process decreased the concentration of selective pathogens by about $1 \log$ from previous treatment. The peel of carrot could provide essential growth nutrients for the microbial flora proliferating on these products. After all washing and peeling treatment, final product was obtained as packed carrot fresh salad. The mean concentrations of total aerobic plate count, Staphylococcus spp. molds and yeast on fresh carrot salads were $4.87 ; 2.08 ; 7.47$ and $2 \log _{10} / 25 \mathrm{~g}$ respectively. The concentration of Staphylococcus spp. yeast and molds increased on final product. This could be related to grating or packaging process that could be a potentiel source of final product contamination. Hence, the use of safe disinfecting treatment to reduce the contamination of final product seems to be necessary. The use of food irradiation at low doses contributes to minimize the microbiological load in fresh-cut vegetables [27]. In this study, the initial total aerobic plate count for carrot salad generally decreased with increasing dose as found previously by Frimpong et al. [28]. Samples were exempt for total aerobic plate count at $1 \mathrm{kGy}$ and $2 \mathrm{kGy}$. After 5 days of storage period, total aerobic plate count was only detected at 0,5 and $1 \mathrm{kGy}$. After 10 days and 15 days of storage period, total aerobic plate count was detected from $0,5 \mathrm{kGy}$ to $2 \mathrm{kGy}$. The effect of irradiation on total aerobic plate count concentration of freshly packaged carrot salads showed a statistically significant difference at $2 \mathrm{kGy}$. This finding suggests that $2 \mathrm{kGy}$ could be most appropriate in total aerobic plate count removal and could increase by 4 to 9 days the shelf life of the product. Vegetable row crops represent $11,7 \%$ of food categories contributing to produce-related outbreaks. Staphylococcus aureus is one of several pathogens that is responsible for $7,9 \%$ of foodborn diseases [2]. Staphylococcus spp. were detected in unirradiated control $\left(2.08 \log _{10} / 25 \mathrm{~g}\right.$ ). The obtained concentration was higher than those described in the previous study of Mohacsi-Farkas et al. [27]. Total removal of Staphylococcus spp. was carried out by irradiation at 0.5 $\mathrm{kGy}$. The lowest irradiation dose was able to remove Staphylococcus spp. contamination even during storage period. Staphylococcus spp. still growing in unirradiated control during storage period with a rate of $1 \mathrm{Log}$ increase. It could be related to the low concentration of these bacteria in the freshly packaged carrot salads. The validity of irradiation at $2 \mathrm{kGy}$ was challenged by artificial inoculation of carrots with Staphylococcus aureus. The dose of $2 \mathrm{kGy}$ resulted in a pathogenfree and hygienic product and could preserve better the ready-toeat shredded carrots. Our result suggests that minimally processed carrots are amenable to irradiation and their storage life can be safely extended by a low dose of irradiation as previously described by other studies $[3,28,29]$. The $\mathrm{D}_{10}$ value reported herein is similar to the ones given for Staphylococcus aureus in food matrices [22,23]. Regarding yeast and molds, their fate was generally increased during the storage period for unirradiated controls as described by other studies [3,27]. In this study, molds were detected after 15 days of storage period for irradiated samples at $2 \mathrm{Gky}$. However, the study of Kamat et al. [3] showed that molds were detected after 5 days of storage period for the irradiated carrot at $2 \mathrm{kGy}$. These findings could be related to processing steps. In our study, a dose of $2 \mathrm{kGy}$ was sufficient for freshly packaged carrot salads preservation from spoilage molds.

\section{Conclusion}

The need for pathogen-free fresh vegetables and fresh cut produce seems to be necessary to provide safe hygienic and healthy food to several types of consumers (immuno-compromised patients, children...). Among ready to eat vegetables, carrot salads, do not undergo a cooking step. Fresh cut vegetables could be contaminated during harvest, postharvest handling, processing steps (trimming, washing, peeling, cutting, slicing and shredding) or packaging and storage. Hence, a safe disinfecting treatment must be overemphasized to ensure good quality and safe salads. The use of gamma irradiation at $2 \mathrm{kGy}$ dose, could be the most appropriate tool to minimize the microbiological load in carrot salad.

\section{Acknowledgment}

This work was supported by the National Center of Nuclear 
Sciences and Technology (CNSTN) Tunisia. We appreciate, Mr Zied Trabelsi for his help and collaboration.

\section{References}

1. ITES (Institue Tunisienne des etudes strategiques). Revue strategique de la securite alimentaire et nutritionnelle en Tunisie. 2017

2. Li M, Baker CA, Danyluk MD, Belanger $P$, Boelaert F, Cressey $P$, et al Identification of Biological Hazards in Produce Consumed in Industrialized Countries: A Review. Journal of Food Protection. 2018; 81: 1171-1186.

3. Kamat AS, Ghadge N, Ramamurthy MS, Alur MD. Effect of low-dose irradiation on shelf life and microbiological safety of sliced carrot. Journal of Science Food and Agriculture. 2005; 85: 2213-2219.

4. Beuchat LR. Pathogenic microorganisms associated with fresh produce. Journal of Food Protection. 1996; 59: 204-216.

5. Wachtel MR, Whitehand LC, Mandrell RE. Association of Escherichia col O157:H7 with Preharvest Leaf Lettuce upon Exposure to Contaminated Irrigation Water. Journal of Food Protection. 2002; 65: 18-25.

6. Al-Lahhama O, El Assib NM, Fayyad M. Impact of treated wastewate irrigation on quality attributes and contamination of tomato fruit. Agricultural Water Management. 2003; 61: 51-62.

7. Bichai F, Polo-Lopez MI, Fernandez Ibanez P. Solar disinfection of wastewater to reduce contamination of lettuce crops by Escherichia coli in reclaimed water irrigation. Water Research. 2012; 46: 6040-6050.

8. Qadir M, Wichelns D, Raschid-Sally L, McCornick PG, Drechsel P, Bahr A, et al. The Challenges of Wastewater Irrigation in Developing Countries. Agricultural Water Management. 2010; 79: 561-568.

9. Bahri A, Basset C, Oueslati F, Brissaud F. Reuse of reclaimed wastewate for golf course irrigation in Tunisia. Water Science and Technology. 2001 43: $117-124$

10. Brackett RE. Incidence, contributing factors, and control of bacteria pathogens in produce. Postharvest Biology and Technology. 1999; 15: 305

11. Francis GA, Thomas C, O'Beirne D. The microbiological safety of minimally processed vegetables. International Journal of Food Science and Technology. 1999; 34: 1-22

12. Rajwar A, Srivastava P, Sahgal M. Microbiology of Fresh Produce: Route of Contamination, Detection Methods, and Remedy. Critical Reviews in Food Science and Nutrition. 2016; 14: 2383-2890.

13. Barth MT, Hankinson $\mathrm{T}$, Zhuang $\mathrm{H}$, Breidt $\mathrm{F}$. Microbiological spoilage of fruits and vegetables: Compendium of the microbiological spoilage of foods and beverages. Food microbiology and food safety. Editors. In: Sperber WH, Doyle MP. Springer, London. 2009; 135-183.

14. Beuchat LR. Ecological factors influencing survival and growth of human pathogens on raw fruits and vegetables. Microbes and Infection. 2002; 4 413-423.

15. Gorny J. Microbial contamination of fresh fruits and vegetables: Microbiology of fruits and vegetables. Editors. In: Sapers GM, Gorny JR, Yousef AE. CRC Press, Boca Raton, FL. 2006; 3-32.
16. Tiimub BM, Kuffour RA, Kwarteng AS. Bacterial Contamination Levels of Lettuce Irrigated with Waste Water in the Kumasi Metropolis. Journal of Biology Agriculture and Healthcare. 2012; 10: 116-127.

17. Maatta J, Lehto M, Kuisma R, Kymalainen H, Maki M. Microbiological Quality of Fresh-Cut Carrots and Process Waters. Journal of Food Protection. 2013; 76: $1240-1244$.

18. Normanno G, Firinu A, Virgilio S, Mula G, Dambrosio A, Poggiu A, et al. Coagulase-positive Staphylococci and Staphylococcus aureus in food products marketed in Italy. International Journal of Food Microbiology. 2005; 98: $73-79$

19. Zhang S, Iandolo JJ, Stewart GC. The enterotoxin D plasmid of Staphylococcus aureus encodes a second enterotoxin determinant (sej). FEMS Microbiology Letters. 1998; 15: 227-233.

20. Tamarapu S, McKillip JL, Drake M. Development of a multiplex polymerase chain reaction assay for detection and differentiation of Staphylococcus aureus in dairy products. Journal of Food Protection. 2001; 64: 664-668.

21. Tirado C, Schmidt K. WHO Surveillance Programme for Control of Foodborne Infections and Intoxications: Preliminary Results and Trends Across Greater Europe. Journal of Infection. 2001; 43: 80-84.

22. Farkas J. Irradiation as a method for decontaminating food: A review International Journal of Food Microbiology. 1998; 44: 189-204.

23. Lamb JL, Gogley JM, Thompson M, Solis D, Sen S. Effect of Low-Dose Gamma Irradiationon Staphylococcus aureus and Product Packagingin Ready-to-Eat Ham and Cheese Sandwiches. Journal of Food Protection. 2002; 65: 1800-1805.

24. Barkai-golan. Safety of Fresh and Fresh-Cut Fruits and Vegetables Following Irradiation for Quality Improvement, Microbial Safety and Phytosanitation of Fresh Produce Irradiation. Editors. In: Barkai golan V, Follet P. Elsevier. 2017; 129-156

25. IFST (Institute of Food Science). The use of irradiation for food quality and food safety. Information statement Institute of food science and Technology. London. 2015; 19.

26. WHO. (World Health Organization). Food irradiation: a technique for preserving and improving the safety of food. World Health Organization. 1998.

27. Mohacsi-Farkas CS, Nyiro-Fekete B, Daood H, Dalmadi I, Kisko G. Improving microbiological safety and maintaining sensory and nutritional quality of pre-cut tomato and carrot by gamma irradiation. Radiation Physics and Chemistry. 2014; 99: 79-85

28. Frimpong GK, Kottoh ID, Ofosu DO, Larbi D. Effect of gamma irradiation on microbial quality of minimally processed carrot and lettuce: A case study in Greater Accra region of Ghana. Radiation Physics and Chemistry. 2015; 110: $12-16$

29. Chervin C, Boisseau P. Quality Maintenance of "Ready-to-eat" Shredded Carrots by Gamma Irradiation. Journal of Food Science. 1994; 59: 359-401. 